\title{
Magnetic navigation behavior and the oceanic ecology of young loggerhead sea turtles
}

\author{
Nathan F. Putman ${ }^{1, *}$, Philippe Verley ${ }^{2}$, Courtney S. Endres ${ }^{1}$ and Kenneth J. Lohmann ${ }^{1}$
}

\begin{abstract}
During long-distance migrations, animals navigate using a variety of sensory cues, mechanisms and strategies. Although guidance mechanisms are usually studied under controlled laboratory conditions, such methods seldom allow for navigation behavior to be examined in an environmental context. Similarly, although realistic environmental models are often used to investigate the ecological implications of animal movement, explicit consideration of navigation mechanisms in such models is rare. Here, we used an interdisciplinary approach in which we first conducted lab-based experiments to determine how hatchling loggerhead sea turtles (Caretta caretta) respond to magnetic fields that exist at five widely separated locations along their migratory route, and then studied the consequences of the observed behavior by simulating it within an ocean circulation model. Magnetic fields associated with two geographic regions that pose risks to young turtles (due to cold wintertime temperatures or potential displacement from the migratory route) elicited oriented swimming, whereas fields from three locations where surface currents and temperature pose no such risk did not. Additionally, at locations with fields that elicited oriented swimming, simulations indicate that the observed behavior greatly increases the likelihood of turtles advancing along the migratory pathway. Our findings suggest that the magnetic navigation behavior of sea turtles is intimately tied to their oceanic ecology and is shaped by a complex interplay between ocean circulation and geomagnetic dynamics.
\end{abstract}

KEY WORDS: Magnetic orientation, Navigation, Magnetoreception, Caretta caretta, Ocean circulation model

\section{INTRODUCTION}

Movement patterns in many animals suggest an impressive ability to navigate and have fueled considerable interest in possible underlying mechanisms (Wiltschko and Wiltschko, 2005; Alerstam, 2006; Thorup and Holland, 2009; Gould and Gould, 2012). Under special circumstances, observations of animal movement patterns in the wild can provide insight into the sensory mechanisms used for navigation within an environmental context (e.g. Alerstam et al., 2001; Nevitt, 2011; Putman et al., 2013a; Putman et al., 2014a). However, multiple alternative hypotheses can often explain the same movement pattern and purely observational data are typically insufficient to identify specific navigation mechanisms (Lohmann et al., 2008a). Experiments performed in a controlled laboratory

\footnotetext{
${ }^{1}$ Department of Biology, University of North Carolina, Chapel Hill, NC 27599, USA. ${ }^{2}$ Institut de Recherche pour le Développement (IRD), UMR 248 MARBEC, Centre de Recherche Halieutique Méditerranéenne et Tropicale, Avenue Jean Monnet, CS 30171, 34203 Séte cedex, France.

*Author for correspondence at present address: National Marine Fisheries Service, Southeast Fisheries Science Center, 75 Virginia Beach Drive, Miami, FL 33149,
} USA (nathan.putman@gmail.com)

Received 20 June 2014; Accepted 20 January 2015 setting, in which one variable is manipulated at a time, reduce ambiguity but necessarily distance the behavior from its environmental context. Increasingly, researchers have addressed this problem by simulating the behavior that was elicited in the laboratory within realistic environmental models (ShamounBaranes et al., 2011; Putman et al., 2012; Staaterman and Paris, 2014). Such techniques are useful for identifying the ecological implications of behavior and generating hypotheses (e.g. Putman et al., 2012; Putman and Naro-Maciel, 2013) that can be further tested with laboratory or field-based experiments (e.g. Mansfield et al., 2014).

In this paper, we examine the magnetic navigation system of hatchling loggerhead sea turtles (Caretta caretta) using a combination of laboratory-based orientation experiments and virtual particle-tracking within an ocean circulation model. This approach has yielded insight into: (1) how young sea turtles use magnetic field information to guide themselves during their initial trans-oceanic migration; and (2) the role that these orientation responses play in the oceanic ecology of this species.

Hatchling loggerheads from Florida, USA begin their transatlantic migration by swimming offshore and into the Gulf Stream (Bolten, 2003; Putman et al., 2010a). After several years of travelling through the North Atlantic Ocean they eventually return to the geographic area from which they originated (Bowen et al., 2004; Lohmann et al., 2008b; Mansfield and Putman, 2013). Laboratory experiments have shown that newly hatched turtles detect both magnetic field intensity (strength) and inclination angle (the angle at which field lines intersect the surface of the Earth) (Lohmann and Lohmann, 1994, 1996). These two parameters provide turtles with geospatial information and enable them to extract both latitudinal and longitudinal information from the Earth's magnetic field (Putman et al., 2011). The emerging picture is that hatchling loggerheads possess of an elaborate set of orientation responses to regional magnetic fields (Lohmann et al., 2001; Merrill and Salmon, 2010; Fuxjager et al., 2011; Putman et al., 2011) and that these responses facilitate movement along their transatlantic migratory route (Lohmann et al., 2012; Putman et al., 2012). We refer to this navigation system as a 'magnetic map', in accordance with recent definitions of this term that encompass all uses of positional information in the Earth's field and make no assumptions about the nature of the internal spatial representation (if any) that a particular animal has (Lohmann et al., 2007; Gould, 2014; Rakhimberdiev et al., 2014; Burke et al., 2014).

Numerous questions remain about the capabilities and function of the turtles' magnetic navigational system (Collette and Collette, 2011; Gould, 2011, 2014). For instance, do turtles inherit a magnetic map that permits them to assess their position anywhere along the North Atlantic subtropical gyre, or do magnetic orientation responses exist in only a few specific geographic areas? Moreover, how do magnetic orientation responses actually shape the paths that turtles take at sea, where ocean currents might 
Table 1. Magnetic-field conditions tested and orientation statistics for hatchling loggerhead turtles

\begin{tabular}{|c|c|c|c|c|c|c|}
\hline Simulated region & $\begin{array}{l}\text { Latitude and longitude of } \\
\text { magnetic coordinates }\end{array}$ & $\begin{array}{l}\text { Magnetic } \\
\text { intensity }(\mu \mathrm{T})\end{array}$ & $\begin{array}{l}\text { Magnetic } \\
\text { inclination (deg) }\end{array}$ & $\begin{array}{l}\text { Mean turtle } \\
\text { heading (deg) }\end{array}$ & $\begin{array}{l}\text { Turtle } \\
\text { Rayleigh } r\end{array}$ & $\begin{array}{l}\text { Turtle } \\
\text { Rayleigh } P\end{array}$ \\
\hline Northern Portugal & $43.0^{\circ} \mathrm{N}, 15.5^{\circ} \mathrm{W}$ & 45.7 & 58.8 & 178 & 0.322 & 0.043 \\
\hline Straits of Gibraltar & $36.0^{\circ} \mathrm{N}, 6.0^{\circ} \mathrm{W}$ & 42.6 & 49.5 & 138 & 0.124 & 0.730 \\
\hline Canary Islands & $30.0^{\circ} \mathrm{N}, 20.0^{\circ} \mathrm{W}$ & 39.4 & 41.1 & 293 & 0.208 & 0.242 \\
\hline Suriname & $11.0^{\circ} \mathrm{N}, 50.5^{\circ} \mathrm{W}$ & 31.8 & 26.1 & 164 & 0.151 & 0.484 \\
\hline Barbados & $13.0^{\circ} \mathrm{N}, 59.6^{\circ} \mathrm{W}$ & 34.1 & 35.5 & 5 & 0.401 & 0.027 \\
\hline
\end{tabular}

transport turtles in directions that differ from those in which they swim?

To address these questions, we first studied orientation responses of hatchling loggerheads to magnetic fields that exist at five different locations in the North Atlantic (Table 1). Three of these fields exist in the eastern Atlantic: between the Azores and northern Portugal, at the Straits of Gibraltar, and near the Canary Islands. The two other fields exist in the western Atlantic: near Barbados and $\sim 700 \mathrm{~km}$ northwest of Suriname and French Guiana. We then simulated the observed orientation within an ocean circulation model to investigate how the behavior might influence the movement paths of individual turtles in a realistic environmental context. Our findings provide evidence that magnetic navigation behavior plays an important role in shaping the migratory trajectories and the oceanic ecology of young loggerhead sea turtles.

\section{RESULTS}

We observed significant differences in orientation of the turtles among the five magnetic treatments (Mardia-Watson-Wheeler Test, $W=17.634, P=0.024$ ). Two fields (northern Portugal and Barbados) elicited oriented swimming. In the northern Portugal field, turtles were oriented southwards (mean angle $=178.3 \mathrm{deg}, \quad r=0.322$, $P=0.043, N=30)$. In the Barbados field, turtles were oriented northwards (mean angle $=5.2 \mathrm{deg}, r=0.401, P=0.027, n=22$ ). The other three fields, however, did not elicit orientation that was statistically distinguishable from random (Fig. 1, Table 1).

Particle-tracking simulations revealed that, at the northern Portugal point, $15.9 \%$ of the passively drifting particles remained at the same latitude or drifted north of it after 60 days (Fig. 2A). In contrast, all particles programmed to swim south at $0.38 \mathrm{~m} \mathrm{~s}^{-1}$ for either $4 \mathrm{~h} \mathrm{day}^{-1}$ (Fig. 2C) or $8 \mathrm{~h} \mathrm{day}^{-1}$ (Fig. 2E) traveled to the south. The lower limit of the preferred thermal niche for North Atlantic loggerheads is approximately $15^{\circ} \mathrm{C}$ (Witt et al., 2010). Mean sea surface temperatures $\leq 14^{\circ} \mathrm{C}$ were encountered by $21.1 \%$ of passively-drifting particles during the 60 day period. By contrast, only $7.3 \%$ of particles swimming $4 \mathrm{~h} \mathrm{day}^{-1}$ and $1.7 \%$ of particles swimming $8 \mathrm{~h} \mathrm{day}^{-1}$ encountered such potentially fatal temperatures.

Particle-tracking simulations at the Barbados point revealed that only $8.9 \%$ of the passive trajectories traveled north along the migratory route via the Antilles Current within 60 days of drift (Fig. 2B). In contrast, when northward swimming was simulated at $4 \mathrm{~h} \mathrm{day}^{-1}, 72.1 \%$ of particles moved northward with the Antilles Current (Fig. 2D); $95.9 \%$ of the particles did so when $8 \mathrm{~h}$ of northward swimming per day was simulated (Fig. 2F).

Particle-tracking simulations were also carried out for the three locations with magnetic fields that did not elicit oriented swimming. For the two locations on the east side of the Atlantic, passive trajectories were variable but generally eastward at the Straits of Gibraltar $(90.7 \%$ of particles entered the Mediterranean Sea) (Fig. 3A) and southward at the Canary Islands (95.5\% of particles drifted south) (Fig. 3B). On the west side of the Atlantic, $94.3 \%$ of particles released at the location near Suriname were advected to the northwest by the North Equatorial Current.

\section{DISCUSSION}

The two regional magnetic fields that elicited orientation responses in the laboratory experiments (the fields from near northern Portugal and from near Barbados) add to the growing list of geographic areas with fields to which turtles respond by adopting consistent directional headings (Lohmann et al., 2001; Merrill and Salmon, 2010; Fuxjager et al., 2011; Putman et al., 2011). Interestingly, three other regional fields failed to elicit any clear orientation response. As a first step toward determining why fields from some geographic locations elicited directional swimming whereas fields from others did not, we consider the results from simulations to investigate likely consequences of drifting passively at each geographic location.

\section{Oriented swimming responses}

In the location near northern Portugal, the southward orientation elicited by the magnetic field is likely to facilitate the turtles' movement along the broad, south-flowing Canary Current System. The southward swimming is consistent with previous results obtained for turtles tested in magnetic fields that exist near this location (Lohmann et al., 2001; Fuxjager et al., 2011, 2014). Results from our particle-tracking simulations suggest that if turtles in this area drift passively, then they will remain in this region for an extended period (Fig. 2). Such an outcome is potentially problematic for young loggerheads because this oceanic region, for much of the year, is too cold for them to survive in (Witt et al., 2010).

Northward orientation elicited by the field near Barbados probably increases the chances of turtles entering the Antilles Current (Fig. 2), which presumably transports them back to the North American coast, where older juveniles take up residence and where nesting eventually occurs (Lohmann et al., 2001; Lohmann and Lohmann, 2003). This finding is consistent with a previous study in which orientation to the northeast was elicited by a magnetic field that exists near Puerto Rico, a behavior that is also likely to facilitate movement into the Antilles Current (Putman et al., 2011). Additionally, particle-tracking experiments imply that northward swimming near Barbados helps young loggerheads avoid the Caribbean Sea (Fig. 2), which might otherwise prolong and complicate their migration (Putman et al., 2011).

\section{Non-oriented swimming responses}

Why magnetic fields that occur at the Straits of Gibraltar, the Canary Islands and north of Suriname did not elicit oriented swimming from turtles (Fig. 1) is unknown. Nevertheless, the lack of orientation responses to these fields may provide important insight into the oceanic ecology of young loggerheads. Orientation responses coupled to specific regional fields may function in some cases to help young turtles vacate or avoid geographic areas that are potentially dangerous because of temperature, predators, limited 


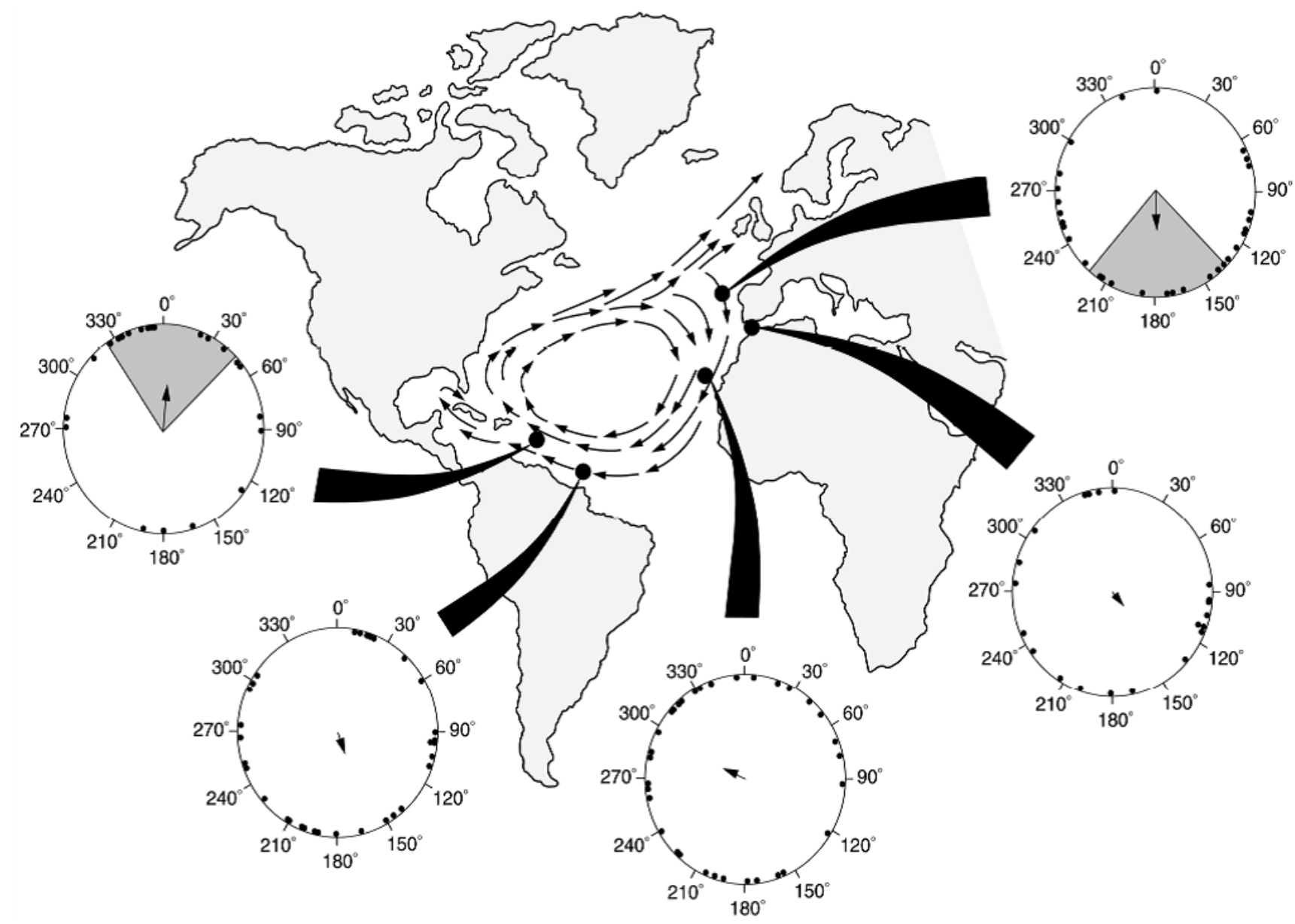

Fig. 1. Orientation responses of turtles to regional magnetic fields in relation to the North Atlantic subtropical gyre. The orientation circles represent the headings of turtles tested in magnetic fields that exist at the locations specified on the map. Each dot within a circle diagram represents the mean angle of a single hatchling. The arrow in the center of each circle indicates the mean angle of the group; the arrow length is proportional to the magnitude of the mean vector $\mathbf{r}$, with the radius of the circle corresponding to $r=1$. The $95 \%$ confidence interval for the mean angle is indicated by gray shading within the circle diagrams for

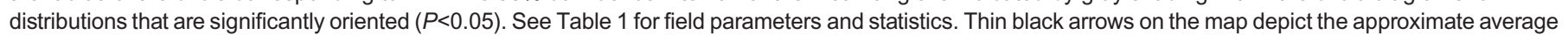
direction of currents at the ocean surface.

food or other factors (Lohmann and Lohmann, 1994; Lohmann et al., 2001; Putman et al., 2012). If so, then fields that occur at locations that are neither dangerous nor unfavorable might not elicit strongly oriented swimming (Lohmann and Lohmann, 1994; Merrill and Salmon, 2010).

The fact that two magnetic fields within the central portion of the Canary Current System failed to elicit oriented swimming is consistent with this hypothesis. Numerous juvenile loggerheads from the southeastern USA are found within this part of the Canary Current, including near the Canary Islands (Monzón-Argüello et al., 2009) and on both the Atlantic and Mediterranean sides of the Straits of Gibraltar (Carreras et al., 2006). Likewise, our analyses with an ocean circulation model did not reveal any obvious risks to turtles of drifting passively at these locations (Fig. 3A,B); the 60 day mean sea surface temperatures experienced by virtual turtles was suitable for loggerheads $\left(>14^{\circ} \mathrm{C}\right)$ in all simulations. Additionally, evidence exists that juvenile loggerheads near the islands of the Azores and Madeira spend extended periods in the Canary Current System and even make seasonal migrations north and south within it (McCarthy et al., 2010). The eastern Atlantic is highly productive (Brochier et al., 2008), suggesting that it is a favorable foraging area for young, pelagic loggerheads. Thus, it appears plausible that orientation responses to the magnetic fields that exist at these two locations have not evolved because the area is generally favorable for young loggerheads and there is no benefit to turtles in moving rapidly through this particular region or attempting to avoid the Mediterranean Sea.

On the western side of the Atlantic, similar factors may account for the absence of orientation elicited by the field that exists near Suriname. In this region, currents are swift and consistently directed to the northwest (Tomczak and Godfrey, 1994), which may sweep turtles safely along the gyre, so that the likelihood of being expelled from the migratory pathway in this area, even when drifting passively, is low (Fig. 3D). Because the direction of transport by currents is strongly and consistently in the migratory direction, there might be little selective pressure favoring oriented swimming in any particular direction.

An important additional consideration is that, in contrast to the Canary Current System, it is not known whether Florida loggerheads actually pass through the waters near Suriname. Thus, an alternative possibility is that Florida loggerheads lack a response to the field near Suriname because the population seldom if ever encounters this field and has thus failed to evolve a response to it. In a previous study, hatchlings failed to respond to a field that exists in a geographic region considerably north of the gyre and outside of the typical migratory pathway (Fuxjager et al., 2011). 

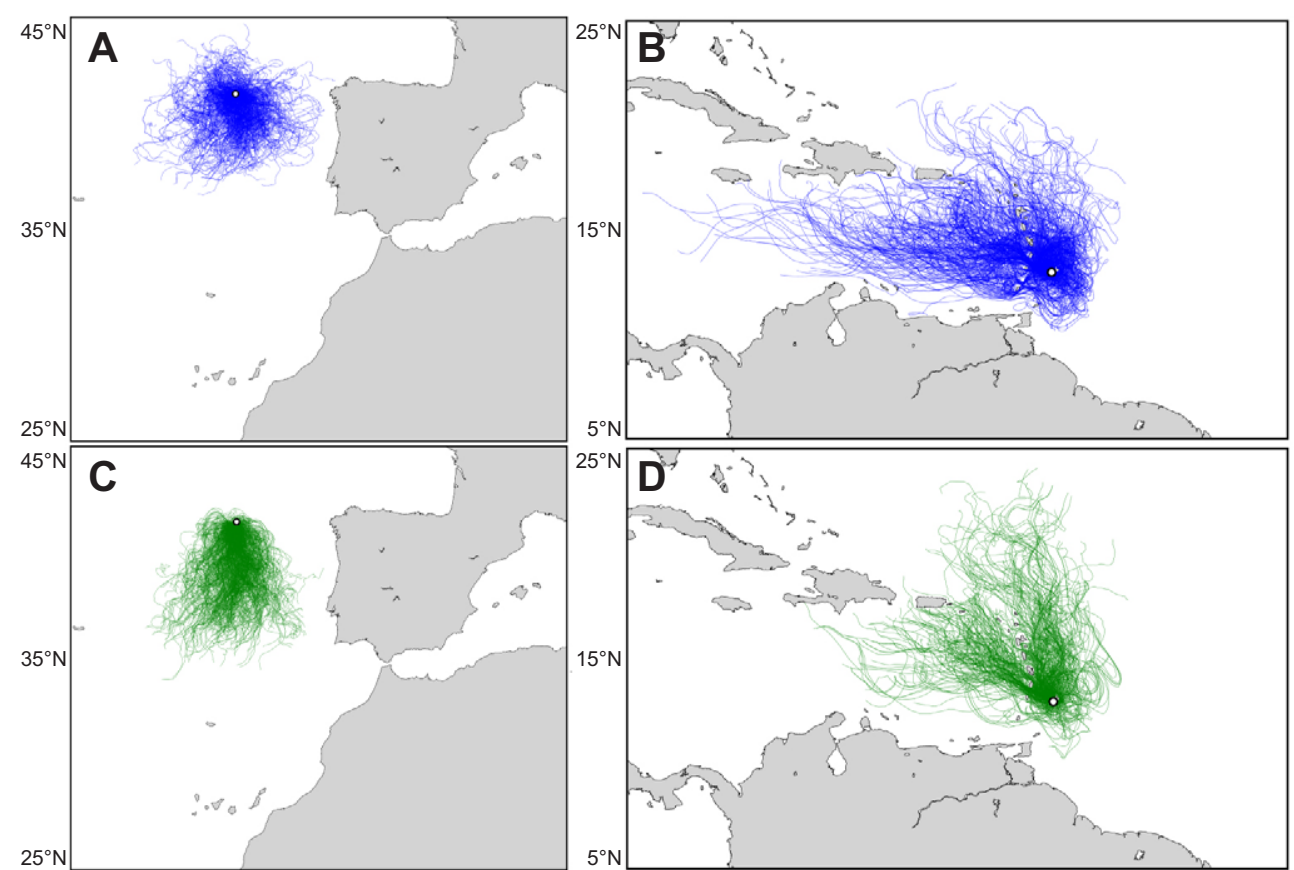

$25^{\circ} \mathrm{N}$
$15^{\circ} \mathrm{N}$
$5^{\circ} \mathrm{N}$
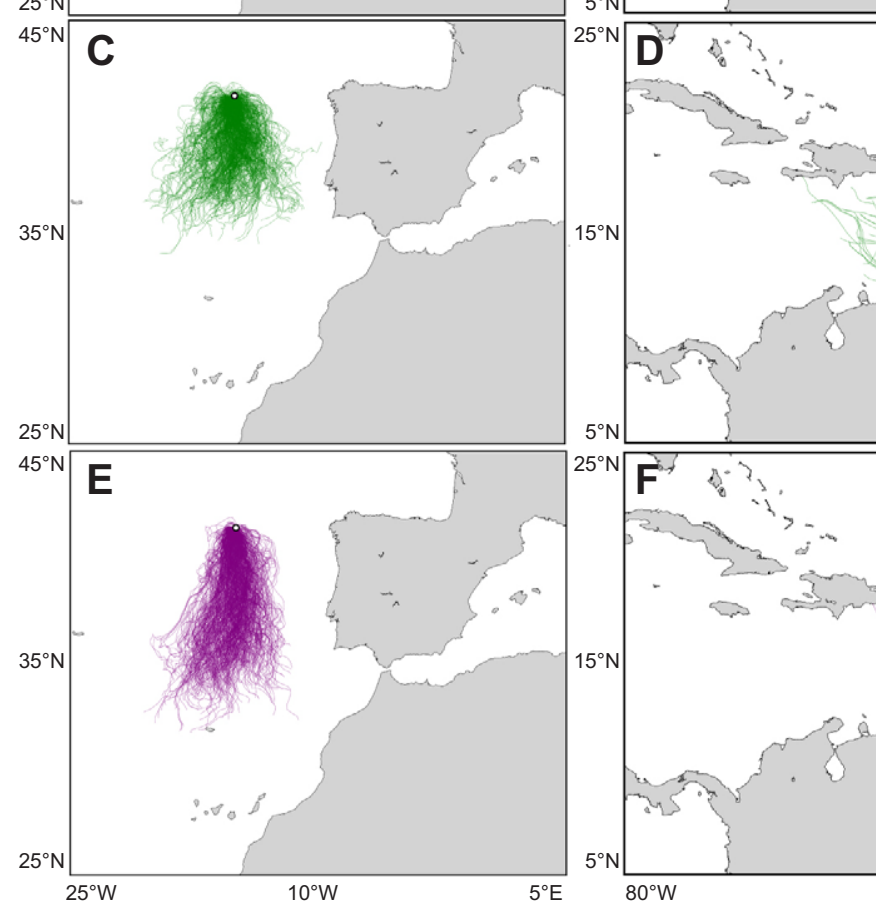

\begin{abstract}
1.
\end{abstract}
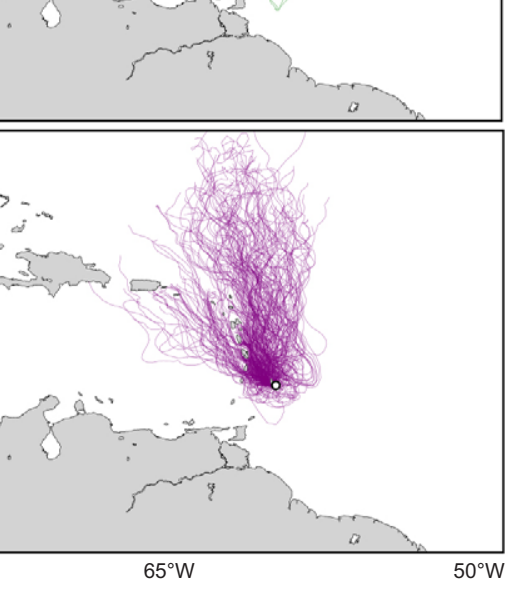

Fig. 2. Simulations investigating the role of magnetic navigation on migratory trajectories of young sea turtles. Virtual particles were released at the two locations in the North Atlantic which had magnetic fields that elicited oriented swimming in laboratory experiments (Fig. 1). Particles were tracked for a simulated 60 day period within the Hybrid Coordinate Ocean Model. Blue trajectories indicate the paths of virtual turtles that drifted passively starting from the $(A)$ north Portugal and

(B) Barbados points. Green lines show the paths of particles programmed to swim

(C) southward from the Portugal point and (D) northward from the Barbados point assuming $4 \mathrm{~h} \mathrm{day}^{-1}$ of swimming at the mean $U_{\text {crit }}\left(0.38 \mathrm{~m} \mathrm{~s}^{-1}\right)$ measured for oceanic stage turtles (Revelles et al., 2007). (E,F) Magenta lines show results of simulations involving $8 \mathrm{~h}$ of swimming each day at the same speed and orientation. For clarity of illustration, only five particles per release event are plotted. See the Materials and methods for simulation details.

\section{Ocean and geomagnetic dynamics}

The environmental conditions and exact patterns of ocean circulation that individual turtles encounter while migrating around the North Atlantic are variable, unpredictable and subject to rapid change. Indeed, as a result of differences in factors such as short-term weather (e.g. tropical storms) or longer-term climatic conditions (e.g. the phase of the North Atlantic Oscillation), it is entirely possible that two different hatchlings starting their migration at the same beach might be transported to very different locations, with one of them reaching an area favorable for development and the other being transported to an area where survival is unlikely. It is noteworthy that, at both the Portugal and Barbados locations, simulating observed turtle orientation narrowed the variation in transport possibilities compared with the scenarios of passive drift (Fig. 2). Thus, in at least some cases, magnetic orientation appears to make the migratory route taken by turtles more predictable, which may be an important aspect of a navigation system that is largely built upon inherited orientation instructions (Lohmann et al., 2012; Putman et al., 2014b,c).

Further complicating matters is the fact that the magnetic field is, itself, gradually changing (Lohmann et al., 2008b; Putman and Lohmann, 2008). Interestingly, recent findings suggest that the migratory routes of some animals (Putman et al., 2013a, 2014a) and the migratory endpoints of others (Brothers and Lohmann, 2015) are influenced by the rate and direction of geomagnetic drift. Indeed, for sockeye and pink salmon, analyses indicate that the drift of the magnetic field accounts for more of the variation in migratory route than the effects of ocean temperature and currents combined (Putman et al., 2014a). A full understanding of the sensory basis of transoceanic migrations by long-distance, marine migrants is likely to require detailed consideration of the numerous sources of variation in ocean conditions and the geomagnetic field. This complex interplay between ocean circulation and geomagnetic dynamics offers a unique conceptual setting to test hypotheses for how animals deal with environmental change and the ecological and evolutionary implications of behavior.

\section{Navigation and ocean ecology}

Our findings add to the accumulating evidence that couplings of regional magnetic fields and directed swimming provide 'building blocks' from which natural selection can sculpt navigational systems capable of guiding first-time migrants along complex migratory routes in the open sea (Lohmann et al., 2001, 2012). This view has been bolstered by the recent discovery of a magnetic navigation system in juvenile Pacific salmon and anadromous trout that bears close resemblance to that of young sea turtles (Putman et al., 2014b,c). In addition, however, the present findings suggest that the magnetic map of young loggerheads is more complicated than previously recognized. Although some fields along the North Atlantic subtropical gyre elicit robust orientation responses, other 

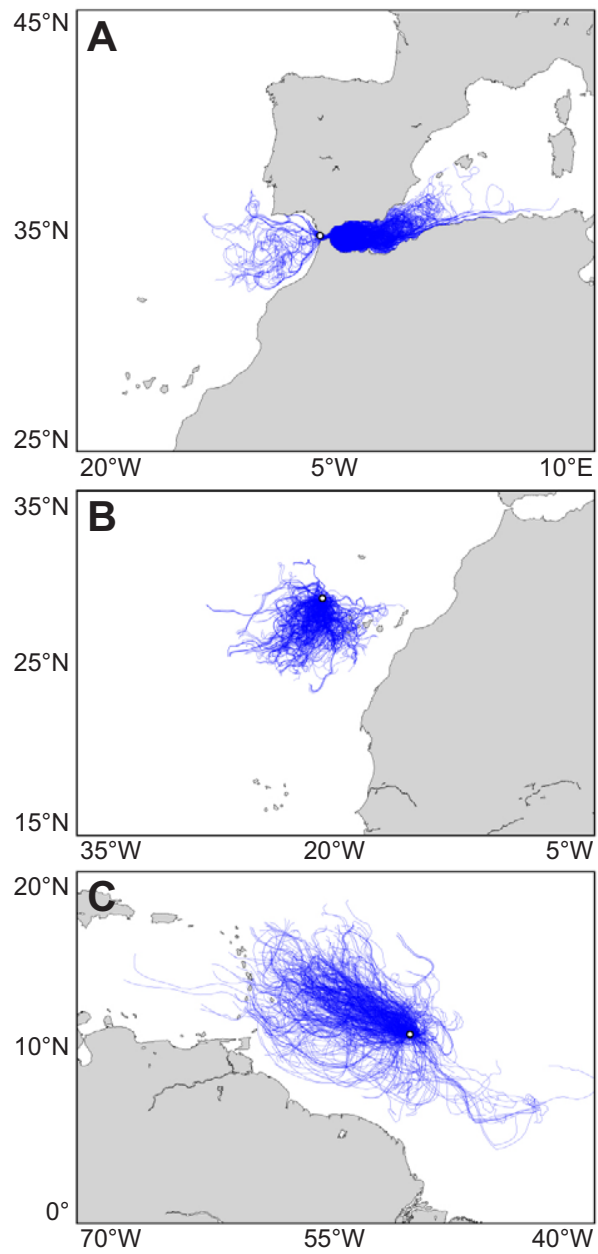

Fig. 3. Simulations illustrating passive transport at locations with magnetic fields that did not elicit orientation. Virtual particles were released at the three locations in the North Atlantic which had magnetic fields that failed to elicit oriented swimming in laboratory experiments (Fig. 1). Particles were tracked for a simulated 60 day period within the Hybrid Coordinate Ocean Model. Blue trajectories indicate the paths of virtual turtles that drifted passively starting from (A) the Straits of Gibraltar, (B) the Canary Islands and (C) northwest of Suriname. For clarity of illustration, only five particles per release event are plotted. See the Materials and methods for simulation details.

fields do not. Analyses of surface currents along the turtles' migratory route suggest that the magnetic navigation responses of turtles are intimately tied to their oceanic ecology. Directed swimming appears to steer turtles into favorable regions of the gyre, in part by helping them leave or avoid areas that pose risks to completing their transoceanic migration (Lohmann et al., 2001, 2012; Merrill and Salmon, 2010; Putman et al., 2012). Additional studies with sea turtles, fishes, and other animals around the globe may provide insight into how navigational mechanisms influence ecological processes such as migration, population connectivity, and patterns of abundance (Nathan, 2008; Chapman et al., 2011; Byron and Burke, 2014).

\section{MATERIALS AND METHODS}

\section{Animals}

Hatchling loggerheads (Caretta caretta Linnaeus 1758) were obtained from Melbourne Beach, FL, USA in July and August of 2007 and 2008. We recorded the date and location of nests deposited in May and June and monitored the emergence of other nests along the beach to predict when hatchlings from a marked nest would emerge. A few hours before the turtles would otherwise have emerged naturally we gently dug into the sand with our hands and removed 15 to 30 hatchlings from the nest. Turtles were immediately placed into lightproof Styrofoam coolers containing a small amount of moist sand, then transported to a nearby facility for experimentation. Hatchlings were maintained outside in the local magnetic field and in complete darkness prior to testing. Each hatchling was subjected to a single $18 \mathrm{~min}$ orientation test. Experiments were conducted between sunset (approximately 20:30 h) and 02:00 h, the period when most loggerhead hatchlings naturally emerge from nests and enter the sea (Witherington et al., 1990). After experiments each night, turtles were released on the beach.

\section{Orientation experiments}

Our experimental approach used 'simulated magnetic displacements', a well-established technique in which magnetic fields existing at some other geographic location are recreated in a laboratory setting and the orientation of animals is measured in response to the stimulus (Beck and Wiltschko, 1988; Lohmann et al., 2004; Fischer et al., 2001). We studied the orientation responses of hatchling loggerhead turtles to five different magnetic fields that exist at different locations along or near the turtles' migratory route in the North Atlantic. Each field was defined by a specific pairing of magnetic intensity and inclination angle. Three of these fields occur within the Canary Current System, a broad and slow south-flowing current on the eastern side of the Atlantic (Tomczak and Godfrey, 1994). The fields chosen exist in locations where young loggerheads from the southeastern USA have been observed: (1) between the Azores and Portugal; (2) at the Straits of Gibraltar; and (3) near the Canary Islands (Carr, 1987; Bolten et al., 1998; Carreras et al., 2006; Monzón-Argüello et al., 2009). The two other fields to which turtles were exposed exist on the western side of the Atlantic, one in the vicinity of Suriname and the other near Barbados. Both locations are near the confluence of the North Equatorial Current and the Guiana Current, two rapid, west-flowing currents that funnel water into the Caribbean Sea (Tomczak and Godfrey, 1994).

Details on the location and parameters for each field are shown in Table 1. The fields used were based on estimates provided by the International Geomagnetic Reference Field Model (IGRF-10) (Macmillan and Maus, 2005) for July 2007 (when the experiment began). Experiments were carried out in July and August of 2007 and 2008.

Methods have been described in detail previously (Lohmann and Lohmann, 1994; Lohmann et al., 2001; Fuxjager et al., 2011, 2014). Briefly, each turtle was tethered to an electronic tracking apparatus in the center of a circular orientation arena composed of fiberglass and measuring $1.22 \mathrm{~m}$ in diameter. The arena was filled with fresh water to a depth of about $30 \mathrm{~cm}$. In each trial, a hatchling was placed into a nylon-Lycra harness that encircled its carapace without impeding swimming (Salmon and Wyneken, 1987). The harness was connected by a $16.5 \mathrm{~cm}$ monofilament line to a Plexiglas tracker-arm measuring $25.5 \mathrm{~cm}$ from its pivot point. The trackerarm was free to rotate in any direction and was connected to a digital encoder inside a plastic post mounted in the center of the arena; the encoder, in turn, was wired to a computer. Thus, the system tracked the orientation of the turtle as it swam, and the computer recorded the position of the turtle (to the nearest degree) every $10 \mathrm{~s}$.

The arena was surrounded by a computerized coil system, which was used to control the magnetic field in which the turtles swam. The coil system consisted of two different coils arranged orthogonally. The coil controlling the horizontal component of the magnetic field measured $2.41 \mathrm{~m}$ on a side and the coil controlling the vertical component measured $2.54 \mathrm{~m}$. Both were constructed in accordance with the 4-coil design by Merritt et al. (1983). Turtles were restricted by tether to the center of the coil in an area defined by a horizontal circle of radius $42 \mathrm{~cm}$ and a vertical area of about $5 \mathrm{~cm}$. In this region, calculated (Merritt et al., 1983) and measured deviations from perfect field uniformity were less than $0.02 \%$ (measurements were made with an Applied Physics Systems tri-axial fluxgate magnetometer, model 520A).

Each turtle began its trial in the local magnetic field (inclination=57.7 deg, intensity $=46.5 \mu \mathrm{T}$ ). The turtle was allowed to establish a course towards a dim light (an LED with peak wavelength $=550 \mathrm{~nm}$ ) suspended $2-3 \mathrm{~cm}$ above the water in magnetic east. This step served to verify that each turtle was 
healthy and capable of maintaining a consistent heading (Lohmann and Lohmann, 1994). Most hatchlings (approximately 95\%) quickly established a course towards the light; the few that failed to do so were replaced before the trial was started. After $10 \mathrm{~min}$, the light was turned off and the magnetic field simultaneously changed to one of the five magnetic fields. Turtles were allowed to adjust for $3 \mathrm{~min}$ to the new field conditions and to swimming in complete darkness. A computer then monitored the direction that each turtle swam during the next $5 \mathrm{~min}$ and calculated a mean heading. Each turtle was tested a single time under one of the five field conditions (Table 1). No more than three turtles from the same nest were tested in the same field. The Rayleigh test was used to determine whether turtles tested in each field were significantly oriented as a group (Batschelet, 1981). The Mardia-WatsonWheeler test was used to determine whether differences in orientation existed among the five different magnetic treatments (Batschelet, 1981).

\section{Simulating magnetic navigation}

To investigate how orientation responses observed in the laboratory might affect migrations in the natural environment, the movement of turtles was simulated using particle-tracking software in combination with a highresolution ocean circulation model. Using well-established techniques (e.g. Putman et al., 2010b, 2012, 2013b), ICHTHYOP v2.21 particletracking software (Lett et al., 2008) tracked the paths of 'virtual turtles' (particles) released into the surface currents of the Global Hybrid Coordinate Ocean Model (HYCOM) (Bleck, 2002). Global HYCOM has output at 00:00 h GMT with a spatial resolution of $0.08 \mathrm{deg}(\sim 7 \mathrm{~km}$ at mid-latitudes). HYCOM also uses data assimilation to produce 'hindcast' model output that better reflects in situ and satellite measurements of oceanic conditions. Global HYCOM thus resolves mesoscale processes such as meandering currents, fronts, filaments and oceanic eddies (Bleck, 2002; Chassignet et al., 2007), which are important in realistically characterizing the movement of turtles (Witherington, 2002; Bolten, 2003; Putman and He, 2013). For advection of particles through HYCOM velocity fields, ICHTHYOP implemented a Runge-Kutta 4th-order timestepping method whereby particle position was calculated each half-hour (Lett et al., 2008).

For simulations, 10 particles were released every 30 days within a $0.08 \mathrm{deg} \times 0.08 \mathrm{deg}$ zone centered at the latitude and longitude that corresponded to the locations of the five magnetic fields presented to hatchling turtles (Table 1). Release dates spanned 9 years, from November 2003 through September 2012; a total of 1080 particles were thus released from each location. All particles were tracked for 60 days.

In the first set of numerical experiments, particles drifted passively and movement was entirely based on the HYCOM velocity fields. A second set of numerical experiments was conducted for the two locations with magnetic fields that elicited oriented swimming (see Results). In these cases, the particles' movement was modeled as a combination of advection by currents and active swimming oriented in the mean direction observed in the corresponding behavioral experiment. Particles were programmed to swim $4 \mathrm{~h}$ and $8 \mathrm{~h} \mathrm{day}^{-1}$ at the mean $U_{\text {crit }}\left(0.38 \mathrm{~m} \mathrm{~s}^{-1}\right)$ measured for oceanic-stage turtles in the eastern Atlantic basin (Revelles et al., 2007). $U_{\text {crit }}$ is the maximum speed that an animal can sustain without experiencing muscular fatigue (Revelles et al., 2007). In still water, this swimming behavior would result in a net movement of $5.47 \mathrm{~km} \mathrm{day}^{-1}$ if the turtle swam for $4 \mathrm{~h}$ and $10.94 \mathrm{~km} \mathrm{day}^{-1}$ if it swam for $8 \mathrm{~h}$. After each hour that a particle swam, the particle randomly picked a new heading within +40 deg of the mean direction that turtles swam in the laboratory experiments.

\section{Acknowledgements}

We thank E. M. Putman and K. Stapput for assistance with experiments and C. M. F. Lohmann for useful discussions regarding the results. This study was authorized under Florida FWCC special permit TP 065.

\section{Competing interests}

The authors declare no competing or financial interests.

\section{Author contributions}

N.F.P., C.S.E. and K.J.L. conceived and designed orientation experiments. N.F.P. and C.S.E. performed orientation experiments. N.F.P. and P.V. conceived and designed particle-tracking simulations. N.F.P. performed particle-tracking simulations. All authors contributed to the interpretation of results. N.F.P. and K.J.L. wrote the paper with input from C.S.E. and P.V.

\section{Funding}

Funding was provided by the National Science Foundation [grant no. IOS-0718991 and IOS-1022005 to K.J.L. and C.M.F.L.]. The modeling work was performed while N.F.P. held a National Research Council Research Associateship Award; PADI Foundation and Lerner Gray Grants were provided to N.F.P. for field-work.

\section{References}

Alerstam, T. (2006). Conflicting evidence about long-distance animal navigation Science 313, 791-794.

Alerstam, T., Gudmundsson, G. A., Green, M. and Hedenström, A. (2001) Migration along orthodromic sun compass routes by Arctic birds. Science 291 300-303.

Batschelet, E. (1981). Circular Statistics in Biology. New York: Academic Press, Inc. Beck, W. and Wiltschko, W. (1988). Magnetic factors control the migratory direction of Pied Flycatchers, Fidecula hypoleuca. Proc. Int. Ornithol. Congress 19 , 1955-1962.

Bleck, R. (2002). An oceanic general circulation model framed in hybrid isopycniccartesian coordinates. Ocean Model. 4, 55-88.

Bolten, A. B. (2003). Active swimmers - passive drifters. In Loggerhead Sea Turtles (ed. A.B. Bolten and B.E. Witherington), pp. 63-78. Washington: Smithsonian Books.

Bolten, A. B., Bjorndal, K. A., Martins, H. R., Dellinger, T., Biscoito, M. J., Encalada, S. and Bowen, B. W. (1998). Transatlantic developmental migrations of loggerhead sea turtles demonstrated by mtDNA sequence analysis. Ecol. Appl. 8, 1-7.

Bowen, B. W., Bass, A. L., Chow, S.-M., Bostrom, M., Bjorndal, K. A., Bolten A. B., Okuyama, T., Bolker, B. M., Epperly, S., Lacasella, E. et al. (2004). Natal homing in juvenile loggerhead turtles (Caretta caretta). Mol. Ecol. 13, 3797-3808. Brochier, T., Ramzi, A., Lett, C., Machu, E., Berraho, A., Fréon, P. and Hernández-León, S. (2008). Modelling sardine and anchovy ichthyoplankton transport in the Canary Current System. J. Plankton Res. 30, 1133-1146.

Brothers, J. R. and Lohmann, K. J. (2015). Evidence for geomagnetic imprinting and magnetic navigation in the natal homing of sea turtles. Curr. Biol. 25, 392-396.

Burke, B. J., Anderson, J. J. and Baptista, A. M. (2014). Evidence for multiple navigational sensory capabilities of Chinook salmon. Aquat. Biol. 20, 77-90.

Byron, C. J. and Burke, B. J. (2014). Salmon ocean migration models suggest a variety of population-specific strategies. Rev. Fish Biol. Fish. 24, 737-756.

Carr, A. (1987). New perspectives on the pelagic stage of sea turtle development. Conserv. Biol. 1, 103-121.

Carreras, C., Pont, S., Maffucci, F., Pascual, M., Barceló, A., Bentivegna, F., Cardona, L., Alegre, F., SanFélix, M., Fernández, G. et al. (2006). Genetic structuring of immature loggerhead sea turtles (Caretta caretta) in the Mediterranean Sea reflects water circulation patterns. Mar. Biol. 149, 1269-1279.

Chapman, J. W., Klaassen, R. H. G., Drake, V. A., Fossette, S., Hays, G. C., Metcalfe, J. D., Reynolds, A. M., Reynolds, D. R. and Alerstam, T. (2011) Animal orientation strategies for movement in flows. Curr. Biol. 21, R861-R870.

Chassignet, E. P., Hurlburt, H. E., Smedstad, O. M., Halliwell, G. R., Hogan, P. J., Wallcraft, A. J., Baraille, R. and Bleck, R. (2007). The HYCOM (HYbrid Coordinate Ocean Model) data assimilative system. J. Mar. Syst. 65, 60-83.

Collett, T. S. and Collett, M. (2011). Animal navigation: following sign-posts in the sea. Curr. Biol. 21, R843-R846.

Fischer, J. H., Freake, M. J., Borland, S. C. and Phillips, J. B. (2001). Evidence for the use of magnetic map information by an amphibian. Anim. Behav. 62, 1-10.

Fuxjager, M. J., Eastwood, B. S. and Lohmann, K. J. (2011). Orientation of hatchling loggerhead sea turtles to regional magnetic fields along a transoceanic migratory pathway. J. Exp. Biol. 214, 2504-2508.

Fuxjager, M. J., Davidoff, K. R., Mangiamele, L. A. and Lohmann, K. J. (2014) The geomagnetic environment in which sea turtle eggs incubate affects subsequent magnetic navigation behaviour of hatchlings. Proc. R. Soc. B 281 20141218

Gould, J. L. (2011). Animal navigation: Iongitude at last. Curr. Biol. 21, R25-R27. Gould, J. L. (2014). Animal navigation: a map for all seasons. Curr. Biol. 24, R153-R155.

Gould, J. L. and Gould, C. G. (2012). Nature's Compass: The Mystery of Animal Navigation. Princeton: Princeton University Press.

Lett, C., Verley, P., Mullon, C., Parada, C., Brochier, T., Penven, P. and Blanke, B. (2008). A Lagrangian tool for modelling ichthyoplankton dynamics. Environ. Model. Software 23, 1210-1214.

Lohmann, K. J. and Lohmann, C. M. F. (1994). Detection of magnetic inclination angle by sea turtles: a possible mechanism for determining latitude. J. Exp. Biol. 194, 23-32.

Lohmann, K. J. and Lohmann, C. M. F. (1996). Detection of magnetic field intensity by sea turtles. Nature 380, 59-61.

Lohmann, K. J. and Lohmann, C. M. F. (2003). Orientation mechanisms in hatchling sea turtles. In Loggerhead Sea Turtles (ed. A.B. Bolten and B.E. Witherington), pp. 44-62. Washington: Smithsonian Books. 
Lohmann, K. J., Cain, S. D., Dodge, S. A. and Lohmann, C. M. F. (2001). Regional magnetic fields as navigational markers for sea turtles. Science 294, 364-366.

Lohmann, K. J., Lohmann, C. M. F., Ehrhart, L. M., Bagley, D. A. and Swing, T. (2004). Animal behaviour: geomagnetic map used in sea-turtle navigation. Nature 428, 909-910.

Lohmann, K. J., Lohmann, C. M. F. and Putman, N. F. (2007). Magnetic maps in animals: nature's GPS. J. Exp. Biol. 210, 3697-3705.

Lohmann, K. J., Lohmann, C. M. F. and Endres, C. S. (2008a). The sensory ecology of ocean navigation. J. Exp. Biol. 211, 1719-1728.

Lohmann, K. J., Putman, N. F. and Lohmann, C. M. F. (2008b). Geomagnetic imprinting: a unifying hypothesis of long-distance natal homing in salmon and sea turtles. Proc. Natl. Acad. Sci. USA 105, 19096-19101.

Lohmann, K. J., Putman, N. F. and Lohmann, C. M. F. (2012). The magnetic map of hatchling loggerhead sea turtles. Curr. Opin. Neurobiol. 22, 336-342.

Macmillan, S. and Maus, S. (2005). International geomagnetic reference field - the tenth generation. Earth Planets Space 57, 1135-1140.

Mansfield, K. M. and Putman, N. F. (2013). Oceanic habits and habitats - Caretta caretta. In Biology of Sea Turtles, Vol. 3 (ed. J. Wyneken, K. J. Lohmann and J. A. Musick), pp. 189-205. Boca Raton: CRC Press, Taylor \& Francis.

Mansfield, K. M., Wyneken, J., Porter, W. P. and Luo, J. (2014). First satellite tracks of neonate sea turtles redefine the 'lost years' oceanic niche. Proc. R. Soc. B Biol. Sci. 281, 20133039.

McCarthy, A. L., Heppell, S., Royer, F., Freitas, C. and Dellinger, T. (2010) Identification of likely foraging habitat of pelagic loggerhead sea turtles (Caretta caretta) in the North Atlantic through analysis of telemetry track sinuosity. Prog. Oceanogr. 86, 224-231.

Merrill, M. W. and Salmon, M. (2010). Magnetic orientation by hatchling loggerhead sea turtles (Caretta caretta) from the Gulf of Mexico. Mar. Biol. 158, 101-112.

Merritt, R., Purcell, C. and Stroink, G. (1983). Uniform magnetic field produced by three, four, and five square coils. Rev. Sci. Instrum. 54, 879

Monzón-Argüello, C., Rico, C., Carreras, C., Calabuig, P., Marco, A. and LópezJuardo, L. F. (2009). Variation in spatial distribution of juvenile loggerhead turtles in the eastern Atlantic and western Mediterranean Sea. J. Exp. Mar. Biol. Ecol. $373,79-86$

Nathan, R. (2008). An emerging movement ecology paradigm. Proc. Natl. Acad. Sci. USA 105, 19050-19051.

Nevitt, G. A. (2011). The neuroecology of dimethyl sulfide: a global-climate regulator turned marine infochemical. Integr. Comp. Biol. 51, 819-825.

Putman, N. F. and He, R. (2013). Tracking the long-distance dispersal of marine organisms: sensitivity to ocean model resolution. J. R. Soc. Interface 10 , 20120979.

Putman, N. F. and Lohmann, K. J. (2008). Compatibility of magnetic imprinting and secular variation. Curr. Biol. 18, R596-R597.

Putman, N. F. and Naro-Maciel, E. (2013). Finding the "lost years" in green turtles: insights from ocean circulation models and genetic analysis. Proc. R. Soc. B Biol. Sci. 280, 20131468.

Putman, N. F., Bane, J. M. and Lohmann, K. J. (2010a). Sea turtle nesting distributions and oceanographic constraints on hatchling migration. Proc. R. Soc. B Biol. Sci. 277, 3631-3637.

Putman, N. F., Shay, T. J. and Lohmann, K. J. (2010b). Is the geographic distribution of nesting in the Kemp's ridley turtle shaped by the migratory needs of offspring? Integr. Comp. Biol. 50, 305-314.
Putman, N. F., Endres, C. S., Lohmann, C. M. F. and Lohmann, K. J. (2011) Longitude perception and bicoordinate magnetic maps in sea turtles. Curr. Biol. 21, 463-466.

Putman, N. F., Verley, P., Shay, T. J. and Lohmann, K. J. (2012). Simulating transoceanic migrations of young loggerhead sea turtles: merging magnetic navigation behavior with an ocean circulation model. J. Exp. Biol. 215, 1863-1870.

Putman, N. F., Lohmann, K. J., Putman, E. M., Klimley, A. P., Quinn, T. P. and Noakes, D. L. G. (2013a). Evidence for geomagnetic imprinting as a homing mechanism in Pacific salmon. Curr. Biol. 23, 312-316.

Putman, N. F., Mansfield, K. M., He, R., Shaver, D. J. and Verley, P. (2013b) Predicting the distribution of oceanic-stage Kemp's ridley sea turtles. Biol. Lett. 9 20130345

Putman, N. F., Jenkins, E. S., Michielsens, C. G. J. and Noakes, D. L. G. (2014a) Geomagnetic imprinting predicts spatio-temporal variation in homing migration of pink and sockeye salmon. J. R. Soc. Interface 11, 20140542.

Putman, N. F., Scanlan, M. M., Billman, E. J., O'Neil, J. P., Couture, R. B., Quinn, T. P., Lohmann, K. J. and Noakes, D. L. G. (2014b). Inherited magnetic map guides ocean navigation in juvenile Pacific salmon. Curr. Biol. 24, 446-450.

Putman, N. F., Meinke, A. M. and Noakes, D. L. G. (2014c). Rearing in a distorted magnetic field disrupts the 'map sense' of juvenile steelhead trout. Biol. Lett. 10, 20140169

Rakhimberdiev, E., Karagicheva, J., Jaatinen, K., Winkler, D. W., Phillips, J. B. and Piersma, T. (2014). Naïve migrants and the use of magnetic cues: temporal fluctuations in the geomagnetic field differentially affect male and female Ruff Philomachus pugnax during their first migration. Ibis 156, 864-869.

Revelles, M., Carreras, C., Cardona, L., Marco, A., Bentivegna, F., Castillo, J. J. de Martino, G., Mons, J. L., Smith, M. B., Rico, C. et al. (2007). Evidence for an asymmetrical size exchange of loggerhead sea turtles between the Mediterranean and the Atlantic through the Straits of Gibraltar. J. Exp. Mar. Biol. Ecol. 349, 261-271.

Salmon, M. and Wyneken, J. (1987). Orientation and swimming behavior of hatchling loggerhead turtles (Caretta caretta L.) during their offshore migration. J. Exp. Mar. Biol. Ecol. 109, 137-153.

Shamoun-Baranes, J., Bouten, W. and van Loon, E. (2011). Integrating meteorology into research on migration. Integr. Comp. Biol. 50, 280-292.

Staaterman, E. and Paris, C. B. (2014). Modelling larval fish navigation: the way forward. ICES J. Mar. Sci. 71, 918-924

Thorup, K. and Holland, R. A. (2009). The bird GPS - long-range navigation in migrants. J. Exp. Biol. 212, 3597-3604.

Tomczac, M. and Godfrey, J. S. (1994). Regional Oceanography: An Introduction New York: Elsevier Science Inc.

Wilstschko, W. and Wiltschko, R. (2005). Magnetic orientation and magnetoreception in birds and other animals. J. Comp. Physiol. A 191, 675-693. Witherington, B. (2002). Ecology of neonate loggerhead turtles inhabiting lines of downwelling near a Gulf Stream front. Mar. Biol. 140, 843-853.

Witherington, B. E., Bjorndal, K. A. and McCabe, C. M. (1990). Temporal pattern of nocturnal emergence of loggerhead turtle hatchlings from natural nests. Copeia 1990, 1165-1168.

Witt, M. J., Hawkes, L. A., Godfrey, M. H., Godley, B. J. and Broderick, A. C. (2010). Predicting the impacts of climate change on a globally distributed species: the case of the loggerhead turtle. J. Exp. Biol. 213, 901-911. 